\title{
Synthesis of bulk lanthanum polyphosphate and other rare earth phosphates through hydrothermal hot-pressing
}

\author{
Hiroaki ONODA*, Taro YAMASAKI \\ Department of Informatics and Environmental Sciences, Faculty of Life and Environmental Sciences, \\ Kyoto Prefectural University, 1-5, Shimogamo Nakaragi-cho, Sakyo-ku, Kyoto 606-8522, Japan
}

Received: April 01, 2013; Revised: July 10, 2013; Accepted: July 11, 2013

(C) The Author(s) 2013. This article is published with open access at Springerlink.com

\begin{abstract}
Bulk samples of lanthanum polyphosphate were synthesized through a hydrothermal hot-pressing (HHP) process. In this process, pressing temperature, pressure and volume of water were varied in order to improve the density and strength of the resulting materials. The strength of the bulk samples was estimated through drilling and ultrasonic treatments. In order to improve the strength of the materials, the use of microwave irradiation was examined. Lanthanum polyphosphate formed porous bulk samples with a filling factor of approximately $70 \%$, which was calculated from real and theoretical densities. With respect to machinable strength, a drilled hole greater than $7.0 \mathrm{~mm}$ in diameter was obtained on some bulk samples, and the diameter of the samples was $14 \mathrm{~mm}$. The HHP process is a useful method for obtaining bulk samples of lanthanum polyphosphate. Bulk lanthanum polyphosphate containing water crumbled easily to a powder form upon ultrasonication. However, these bulk samples retained their shape upon ultrasonication, despite containing water, after exposure to microwave irradiation, and also experienced minimal weight loss. Furthermore, to study the effect of microwave heating, bulk lanthanum orthophosphate, yttrium orthophosphate and polyphosphate were also examined.
\end{abstract}

Keywords: lanthanum polyphosphate; hydrothermal hot-pressing (HHP) process; machinable strength; vibration strength; microwave heating

\section{Introduction}

Phosphates have been widely utilized as ceramic materials, catalysts, adsorbents, fluorescent materials, dielectric substances, metal surface treatments, fertilizers, detergents, food additives, fuel cells and pigments. Of all the known phosphate materials, rare earth phosphates are particularly important, owing to their high melting points and low solubilities in acidic

\footnotetext{
* Corresponding author.

E-mail: onoda@kpu.ac.jp
}

and basic solutions [1].

For their various applications, phosphates can be in the form of powders, bulk samples, or thin layers. As phosphates decompose to oxides at high temperatures through the loss of $\mathrm{P}_{2} \mathrm{O}_{5}$, it is difficult to obtain bulk samples of phosphates through standard sintering techniques. As a novel synthetic process, the use of hydrothermal hot-pressing (HHP) method has been investigated [2-7]. In this method, a mixture containing the powder starting material and a small amount of water is sintered at relatively low temperatures, which typically produces porous phosphate materials. The advantages of this method are 
low sintering temperatures and porous bulk products that it typically produces. However, although many porous phosphate bulk samples have been synthesized through HHP, these bulk samples are not physically strong enough for use in many applications. Therefore, it is necessary to improve the physical strength of bulk samples; this physical strength is related to the filling factor. The filling factor is calculated by the real and theoretical densities, and the bulk samples with a high filling factor typically possess high physical strength. The strength against the mechanical processing is also an important factor in the formation of phosphate bulk samples. Bulk samples with a high density are usually hard; however, they may also be fragile. The porous structure can be deformed by the impact of mechanical treatment. Another important factor to consider is how the sample pellet can contain water easily during the HHP process, as microwave heating is expected to sinter the sample pellet in a short duration of time.

In this study, lanthanum polyphosphate was synthesized by heating a mixture of lanthanum oxide and phosphoric acid, and subsequently subjecting it to the HHP process. The lanthanum polyphosphate bulk samples were assessed by examining their density, filling factor, machinable strength and vibration strength. Bulk samples heated with microwave irradiation were also examined. Furthermore, in order to study the machinability and vibration strength of bulk rare earth phosphates, lanthanum orthophosphate, yttrium orthophosphate and polyphosphate were used.

\section{Experiment}

Lanthanum oxide, $\mathrm{La}_{2} \mathrm{O}_{3}$, was mixed with phosphoric acid in the molar ratio of $\mathrm{La}: \mathrm{P}=1: 3$. This ratio was determined from the chemical composition of lanthanum polyphosphate, $\mathrm{La}\left(\mathrm{PO}_{3}\right)_{3}$. The mixture was then heated at $700{ }^{\circ} \mathrm{C}$ for $1 \mathrm{~h}$. The resulting product was characterized by X-ray diffraction (XRD) analyses. The XRD patterns were recorded on an X-ray diffractometer (MiniFlex; Rigaku Corp.) using monochromatic $\mathrm{Cu} \mathrm{K} \alpha$ radiation $(30 \mathrm{kV}, 15 \mathrm{~mA}$, $\left.3\left({ }^{\circ}\right) / \mathrm{min}\right)$.

The mixtures of the sample powders $(1 \mathrm{~g})$ and water $(0-0.4 \mathrm{ml})$ were placed in a mold and mechanically pressed with a uniaxial pressure of 5-30 MPa for $1 \mathrm{~h}$, using the HHP process. As the mold had a slight excess of space, water could be volatilized during the sintering process. The filling factor was calculated using the density of the obtained lanthanum polyphosphate bulk samples and the ideal density of the crystallized lanthanum polyphosphate.

The machinable strength was estimated from the diameter of a hole that was drilled into the $14 \mathrm{~mm}$-diameter pellet. The vibration strength was estimated by the following method. Bulk samples were first placed in a $100 \mathrm{ml}$ beaker with $100 \mathrm{ml}$ of water, and then ultrasonicated for $60 \mathrm{~s}$. The bulk samples were then collected and dried, and the weight loss was calculated. In order to improve the strength prior to ultrasonic treatment, the bulk samples were heated by microwave irradiation $(2450 \mathrm{MHz}, \mathrm{EMO}-706$; IRIS OHYAMA INC.). Because phosphate bulk materials contained a small amount of water, the effects of sintering by microwave irradiation for a short duration were expected. As a comparison to the microwave-heated bulk samples, bulk phosphates were also heated with an electrical furnace under ambient conditions.

Furthermore, other rare earth phosphates were also used to study the effects of microwave heating. Lanthanum orthophosphate, $\mathrm{LaPO}_{4}$, was synthesized by heating a mixture of $\mathrm{La}_{2} \mathrm{O}_{3}$ and phosphoric acid in the ratio of $\mathrm{La}: \mathrm{P}=1: 1$ at $700{ }^{\circ} \mathrm{C}$ for $1 \mathrm{~h}$. Yttrium ortho- and polyphosphates were obtained by heating the mixtures of yttrium oxide and phosphoric acid in $\mathrm{Y}: \mathrm{P}=1: 1$ and $\mathrm{Y}: \mathrm{P}=1: 3$ at $700{ }^{\circ} \mathrm{C}$ for $1 \mathrm{~h}$, respectively. Also, these phosphates were then subjected to the HHP process. The obtained bulk rare earth phosphates were examined with the same method as the bulk lanthanum polyphosphate.

\section{Results and discussion}

\section{1 Chemical composition of lanthanum polyphosphates}

Figure 1 shows the XRD pattern of the sample prepared with the ratio of La:P $=1: 3$; this sample exhibits the peaks of lanthanum polyphosphate, $\mathrm{La}\left(\mathrm{PO}_{3}\right)_{3}$. Other compounds are not detected in the XRD pattern of the sample. In this work, the XRD patterns of the samples do not change after the HHP process, microwave heating, or calcination in an electric furnace. It is important to note that the samples display no change in the XRD patterns after sintering. 


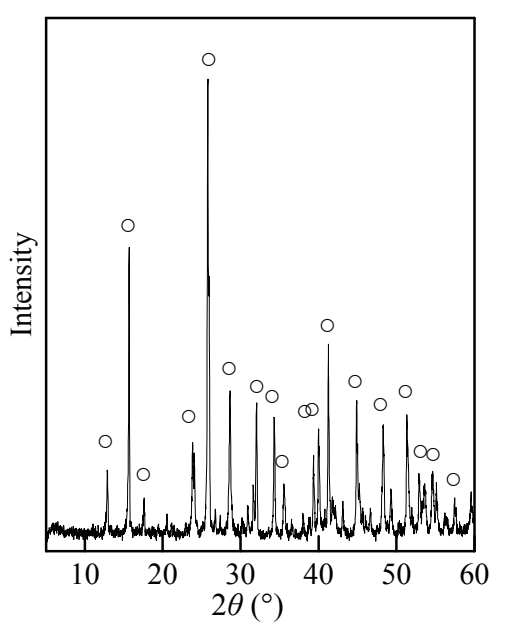

Fig. 1 XRD pattern of the sample prepared with $\mathrm{La}: \mathrm{P}=1: 3 ; \circ: \mathrm{La}\left(\mathrm{PO}_{3}\right)_{3}$.

\section{2 Density of bulk lanthanum polyphosphates}

The density of the bulk samples is an important property owing to its correlation with its physical strength. Figures 2-4 show the densities and filling factors of lanthanum phosphate bulk samples. Temperature does not have a strong influence on the density of the lanthanum phosphate bulk samples (Fig. 2). The filling factor is approximately $70 \%$, which is calculated from the ideal density of lanthanum polyphosphate. This percentage is lower than that of the phosphate bulk samples synthesized by the HHP process in the previous experiments [8-10]. The low filling factor can potentially absorb the physical stress. The phosphate bulk samples synthesized with $0.1 \mathrm{ml}$ of water exhibit a higher density than those synthesized without any water (Figs. 2 and 3). The increase in the volume of added water indicates a weak ability to improve the density of bulk samples synthesized through the HHP process (Fig. 3). As the pressure used in the HHP process increases, the bulk density typically improves (Fig. 4).

\section{3 Machinable strength of bulk lanthanum polyphosphates}

In addition to the physical strength of bulk samples, the change of the bulk shape is an important factor in its use as a material [11]. Inorganic materials are generally resilient to physical stress, but may be prone to cracking because of mechanical treatment. Therefore, the strength against mechanical treatment is

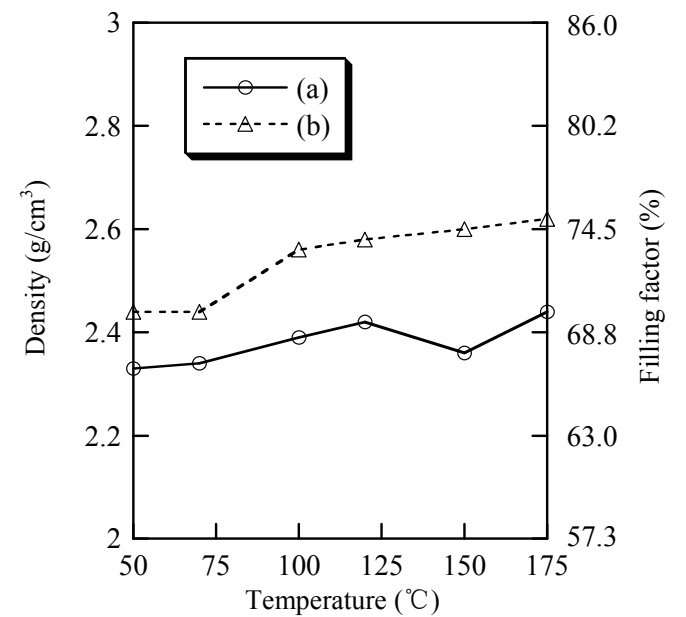

Fig. 2 Temperature effects on the density and filling factor of the bulk lanthanum polyphosphates with water volume of (a) $0 \mathrm{ml}$ and (b) $0.1 \mathrm{ml}(20 \mathrm{MPa})$.

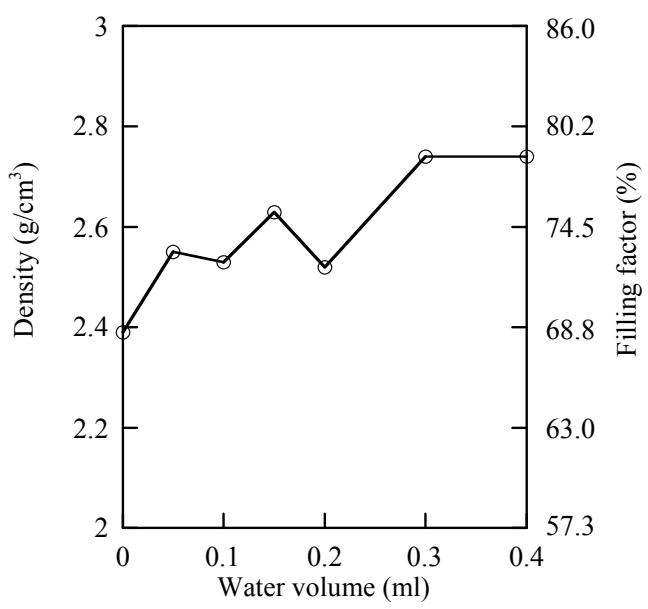

Fig. 3 Water volume in relation to the density and filling factor of the bulk lanthanum polyphosphates $\left(100{ }^{\circ} \mathrm{C}, 20 \mathrm{MPa}\right)$.

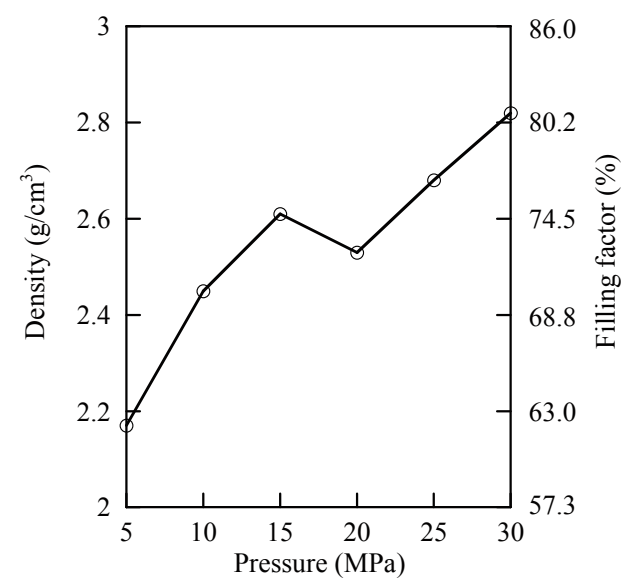

Fig. 4 Pressure effects on the density and filling factor of the bulk lanthanum polyphosphates $\left(100{ }^{\circ} \mathrm{C}\right.$, water volume $\left.=0.1 \mathrm{ml}\right)$. 
studied by using a drilling process. Figure 5 shows the photographs of bulk samples before and after drilling treatment. The bulk samples have diameter of $14 \mathrm{~mm}$. The diameter of the drill begins at $4.0 \mathrm{~mm}$, and increases at a rate of $0.5 \mathrm{~mm}$ for each additional test. The maximum diameter obtained without the cracking is recorded for the phosphate bulk samples.

Table 1 shows the maximum diameter of drilling for the lanthanum polyphosphate bulk samples prior to cracking. The mark " $\mathrm{x}$ " corresponds to no record, or that the bulk samples were cracked by the $4.0 \mathrm{~mm}$ drill. The bulk sample synthesized at $100{ }^{\circ} \mathrm{C}$ with $0.4 \mathrm{ml}$ of water is the only sample with no record. In the

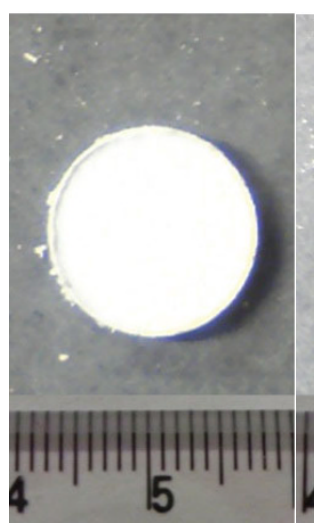

(a)

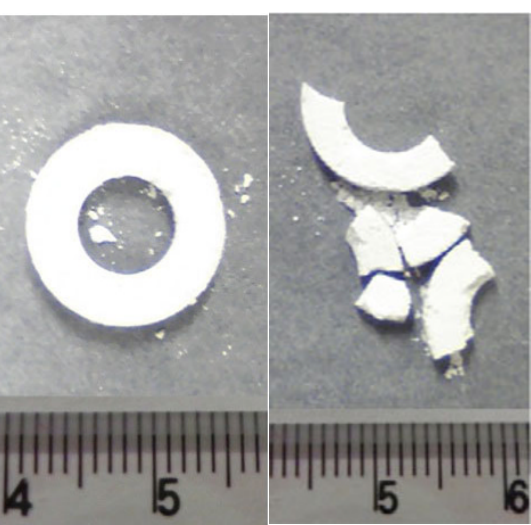

(c)
Fig. 5 Photographs of the lanthanum polyphosphate bulk samples: (a) without mechanical treatment; (b) after drilling a hole with a diameter of $7.0 \mathrm{~mm}$; (c) after drilling a hole with a diameter of $7.5 \mathrm{~mm}$.

Table 1 Maximum diameters of the drilled holes in the bulk lanthanum polyphosphates without cracking: (I) temperature dependence, $20 \mathrm{MPa}$; (II) pressure dependence, $100{ }^{\circ} \mathrm{C}$; (III) volume of water dependence, $100{ }^{\circ} \mathrm{C}$ (Unit: $\mathrm{mm}$ )

\begin{tabular}{cccccc}
\hline & \multicolumn{5}{c}{ Temperature $\left({ }^{\circ} \mathrm{C}\right)$} \\
\cline { 2 - 6 } Water volume $(\mathrm{ml})$ & 50 & 70 & 100 & 120 & 150 \\
\hline 0 & 5.5 & 4.0 & 4.5 & 6.0 & 5.0 \\
0.1 & 5.5 & 6.0 & 4.5 & 4.0 & 4.5 \\
\hline$(\mathrm{II})$ & \multicolumn{5}{c}{ Pressure $(\mathrm{MPa})$} \\
\cline { 2 - 6 } Water volume $(\mathrm{ml})$ & 5 & 10 & 15 & 20 & 25 \\
\hline 0.1 & 4.0 & 6.0 & 4.0 & 4.5 & 7.0 \\
\hline (III) & \multicolumn{5}{c}{ Water volume $(\mathrm{ml})$} \\
\cline { 2 - 6 } Pressure $(\mathrm{MPa})$ & 0 & 0.1 & 0.2 & 0.3 & 0.4 \\
\hline 20 & 4.5 & 4.5 & 6.0 & 4.0 & $\mathrm{x}$ \\
\hline
\end{tabular}

previous studies [12], cracking occurred in many bulk samples synthesized from lanthanum orthophosphate. Lanthanum polyphosphate bulk samples are typically more resistant to drilling than lanthanum orthophosphate bulk samples. Since the samples prepared with the ratio of $\mathrm{La}: \mathrm{P}=1: 3$ have a higher machinable strength than the samples prepared with the ratio of $\mathrm{La}: \mathrm{P}=1: 1$, the phosphorus-rich composition is related to the stickiness against physical stress. Many conditions produce a drilled hole with a diameter larger than $6.0 \mathrm{~mm}$. A drilled hole greater than $7.0 \mathrm{~mm}$ is obtained on some bulk samples with a diameter of $14 \mathrm{~mm}$ for the entire sample. The pressing temperature, pressure and volume of water do not have a clear influence on the strength of the bulk materials against the drilling.

\section{4 Vibration strength of bulk lanthanum polyphosphates}

In previous work, the bulk samples synthesized by HHP were weak to ultrasonication in water [12]. Since the bulk samples can easily contain water, microwave heating for a short amount of time is expected to improve the strength of bulk phosphates in water. Therefore, some bulk samples were put in water after microwave irradiation, treated with ultrasonication, and then collected. The weight loss of bulk samples is shown in Table 2. A small weight loss corresponds to high vibration strength in the bulk phosphates. The bulk samples that were not heated in the microwave crumbled to powders in water before ultrasonic treatment (Table 2(a)). Alternatively, bulk samples heated in a microwave display little weight loss after ultrasonic treatment (Table 2(b), Table 2(c) and Table 2(d)). The microwave irradiation is effective in maintaining the bulk shape in water. After ultrasonic treatment for $180 \mathrm{~s}$, the weight loss of the bulk sample becomes large (Table 2(e)). The weight loss is about $20 \%$ for the bulk sample synthesized at $150{ }^{\circ} \mathrm{C}$ (Table 2(f)). Since the samples lose water as a result of the high pressing temperature, the microwave heating effect is minimal. Bulk samples synthesized at $10 \mathrm{MPa}$ without water crumbled to powders in water after ultrasonic treatment for $60 \mathrm{~s}$ (Table $2(\mathrm{~g})$ and Table 2(h)). The $10 \mathrm{MPa}$ pressure is too low, and the bulk sample obtained without water is not greatly affected by microwave heating. 
Table 2 Weight losses of bulk lanthanum polyphosphates

\begin{tabular}{|c|c|c|c|c|c|c|}
\hline & $\begin{array}{c}\text { Pressure } \\
(\mathrm{MPa})\end{array}$ & $\begin{array}{c}\text { Water } \\
(\mathrm{ml})\end{array}$ & $\begin{array}{c}\text { Temperature } \\
\left({ }^{\circ} \mathrm{C}\right)\end{array}$ & $\begin{array}{c}\text { Microwave } \\
\text { (s) }\end{array}$ & $\begin{array}{l}\text { Ultrasound } \\
\text { (s) }\end{array}$ & $\begin{array}{c}\text { Weight } \\
\text { loss } \\
(\%)\end{array}$ \\
\hline (a) & 20 & 0.1 & 100 & 0 & 60 & 100 \\
\hline (b) & 20 & 0.1 & 100 & 30 & 60 & 7.24 \\
\hline (c) & 20 & 0.1 & 100 & 60 & 60 & 4.38 \\
\hline (d) & 20 & 0.1 & 100 & 180 & 60 & 6.34 \\
\hline (e) & 20 & 0.1 & 100 & 30 & 180 & 59.28 \\
\hline (f) & 20 & 0.1 & 150 & 30 & 60 & 22.50 \\
\hline (g) & 10 & 0.1 & 100 & 30 & 60 & 100 \\
\hline (h) & 20 & 0 & 100 & 30 & 60 & 100 \\
\hline
\end{tabular}

\section{5 Microwave heating of bulk lanthanum polyphosphates}

Table 3 shows the maximum diameter of the drilled hole in lanthanum polyphosphate pellets before and after microwave heating. The maximum diameter decreases after microwave heating. Upon microwave irradiation, the bulk samples lost water and became hard yet fragile.

The bulk samples heated by microwave are compared with bulk samples heated in an electric furnace (Table 4). The bulk samples heated in an electric furnace support large drilled holes, with diameters of $6.0 \mathrm{~mm}$ and $6.5 \mathrm{~mm}$. The weight loss is

Table 3 Maximum diameters of drilled holes in lanthanum polyphosphate pellets with and without microwave heating ( $30 \mathrm{~s}$ )

\begin{tabular}{ccccc}
\hline $\begin{array}{c}\text { Pressure } \\
(\mathrm{MPa})\end{array}$ & $\begin{array}{c}\text { Water } \\
(\mathrm{ml})\end{array}$ & $\begin{array}{c}\text { Temperature } \\
\left({ }^{\circ} \mathrm{C}\right)\end{array}$ & $\begin{array}{c}\text { Without } \\
(\mathrm{mm})\end{array}$ & $\begin{array}{c}\text { With } \\
(\mathrm{mm})\end{array}$ \\
\hline 20 & 0.1 & 100 & 4.5 & 4.5 \\
20 & 0.1 & 150 & 4.5 & 4.0 \\
10 & 0.1 & 100 & 6.0 & 4.0 \\
20 & 0 & 100 & 4.5 & 4.5 \\
\hline
\end{tabular}

Table 4 Heating effects of bulk lanthanum polyphosphates on machinable and vibration strengths (HHP temperature $=100{ }^{\circ} \mathrm{C}$, pressure $=20 \mathrm{MPa}$, water volume $=0.1 \mathrm{ml}$ )

\begin{tabular}{ccccc}
\hline Heating & $\begin{array}{c}\text { Temperature } \\
\left({ }^{\circ} \mathrm{C}\right)\end{array}$ & $\begin{array}{c}\text { Time } \\
(\mathrm{s})\end{array}$ & $\begin{array}{c}\text { Maximum }^{*} \\
\text { diameter }^{*} \\
(\mathrm{~mm})\end{array}$ & $\begin{array}{c}\text { Weight } \\
\text { loss } \\
(\%)\end{array}$ \\
\hline - & - & 0 & 4.5 & 100 \\
Microwave & - & 30 & 4.5 & 7.24 \\
Microwave & - & 60 & 5.0 & 4.38 \\
Microwave & - & 180 & 4.5 & 6.34 \\
Electric furnace & 200 & 3600 & 6.0 & 2.36 \\
Electric furnace & 300 & 3600 & 6.5 & 1.28 \\
\hline *: machinable strength.**: vibration strength.
\end{tabular}

*: machinable strength; **: vibration strength. less than $5 \%$ in these bulk samples. These results are highly desirable; however, the heating time is too long for bulk samples heated in an electric furnace. The rising temperature ratio is $5 \mathrm{~K} / \mathrm{min}$ in the electric furnace. Therefore, the bulk samples are heated for longer than $3600 \mathrm{~s}$ in the electric furnace. Microwave irradiation, which is less than $180 \mathrm{~s}$, is effective in improving the strength against ultrasonication for the bulk samples synthesized by the HHP process.

\section{6 Other rare earth phosphates}

According to the XRD analyses, lanthanum orthophosphate, yttrium ortho- and polyphosphates were obtained through heating (Fig. 6). These rare earth phosphates formed the bulk samples through the HHP process. XRD patterns of the samples exhibit no change after HHP, microwave heating, or heating in an electric furnace. In order to study the effects of microwave irradiation, the machinable and vibration strengths of these bulk samples were measured. Some of the bulk yttrium ortho- and polyphosphates broke upon microwave heating. These results could be attributed to lanthanum being a light rare earth element and yttrium being a heavy rare earth element. Therefore, HHP conditions of the yttrium ortho- and polyphosphates are different from those of lanthanum polyphosphate. Table 5 shows the maximum diameter of a drilled hole on bulk rare earth phosphates. Yttrium orthophosphate has a larger diameter with increasing microwave irradiation time. Alternatively, lanthanum orthophosphate exhibits little change in its machinable strength. The difference in the machinable strength decreases with decreasing level of sintering. Table 6 displays the vibration strength of the bulk rare earth phosphates in water. Bulk lanthanum orthophosphate decomposed during ultrasonication for $60 \mathrm{~s}$. The bulk yttrium orthophosphate heated at $200{ }^{\circ} \mathrm{C}$ in an electric furnace exhibits a large weight loss (48\%). Alternatively, the bulk yttrium orthophosphate after microwave irradiation exhibits less weight loss. Microwave irradiation for a short amount of time is an effective method to improve the vibration strength of bulk yttrium orthophosphate. Microwave irradiation may potentially improve the machinable and vibration strengths of bulk rare earth phosphates; however, it is not always a suitable method for all rare earth phosphates. 


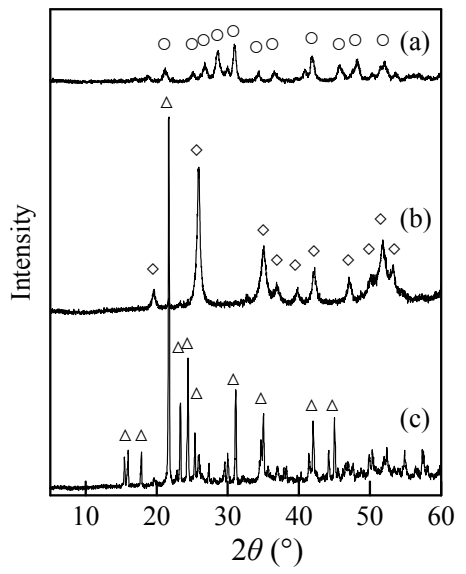

Fig. 6 XRD patterns of samples prepared with (a) $\mathrm{La}: \mathrm{P}=1: 1$, (b) $\mathrm{Y}: \mathrm{P}=1: 1$, and (c) $\mathrm{Y}: \mathrm{P}=1: 3$; 0 : $\mathrm{LaPO}_{4}, \diamond: \mathrm{YPO}_{4}, \triangle: \mathrm{Y}\left(\mathrm{PO}_{3}\right)_{3}$.

Table 5 Machinable strength (maximum diameter of hole, mm) of bulk rare earth phosphates

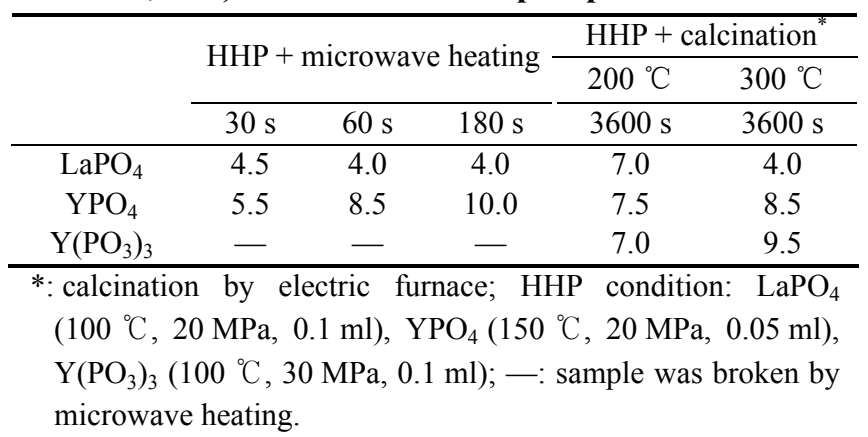

Table 6 Vibration strength (weight loss by ultrasound, \%) of bulk rare earth phosphates

\begin{tabular}{|c|c|c|c|c|c|}
\hline & \multirow{2}{*}{\multicolumn{3}{|c|}{$\mathrm{HHP}+$ microwave heating }} & \multicolumn{2}{|c|}{ HHP + calcination $^{*}$} \\
\hline & & & & \multirow{2}{*}{$\frac{200{ }^{\circ} \mathrm{C}}{3600 \mathrm{~s}}$} & \multirow{2}{*}{$\frac{300{ }^{\circ} \mathrm{C}}{3600 \mathrm{~s}}$} \\
\hline & $30 \mathrm{~s}$ & $60 \mathrm{~s}$ & $180 \mathrm{~s}$ & & \\
\hline $\mathrm{LaPO}_{4}$ & 100 & 100 & 100 & 100 & 1.40 \\
\hline $\mathrm{YPO}_{4}$ & 4.44 & 3.16 & 0.86 & 48.13 & 0.29 \\
\hline $\mathrm{Y}\left(\mathrm{PO}_{3}\right)_{3}$ & - & - & - & 2.10 & 0.39 \\
\hline \multicolumn{6}{|c|}{$\begin{array}{l}\text { calcination by electric furnace; } \mathrm{HHP} \text { condition: } \mathrm{LaPO}_{4} \\
\left(100{ }^{\circ} \mathrm{C}, 20 \mathrm{MPa}, 0.1 \mathrm{ml}\right), \mathrm{YPO}_{4}\left(150{ }^{\circ} \mathrm{C}, 20 \mathrm{MPa}, 0.05 \mathrm{ml}\right) \text {, } \\
\mathrm{Y}\left(\mathrm{PO}_{3}\right)_{3}\left(100{ }^{\circ} \mathrm{C}, 30 \mathrm{MPa}, 0.1 \mathrm{ml}\right) ;- \text { : sample was broken by } \\
\text { microwave heating. }\end{array}$} \\
\hline
\end{tabular}

\section{Conclusions}

Bulk lanthanum polyphosphate samples were synthesized using HHP process. The resulting bulk samples possessed a filling factor of approximately $70 \%$. A drilled hole greater than $7.0 \mathrm{~mm}$ in diameter was obtained on some pellet-shaped bulk samples of $14 \mathrm{~mm}$ in diameter. The bulk sample that was not exposed to microwave irradiation crumbled to powders in water, but bulk samples heated by microwave irradiation exhibited little weight loss after ultrasonic treatment. As demonstrated by the bulk sample synthesized through HHP containing a certain degree of water, microwave irradiation for a short amount of time can potentially improve the strength of the material against ultrasonic treatment.

Open Access: This article is distributed under the terms of the Creative Commons Attribution License which permits any use, distribution, and reproduction in any medium, provided the original author(s) and the source are credited.

\section{References}

[1] Onoda H, Tange K, Tanaka I. Influence of lanthanum addition on preparation and powder properties of cobalt phosphates. J Mater Sci 2008, 43: 5483-5488.

[2] Takimura M, Nagata H, Yamasaki Y, et al. Synthesis and characterization of bulky FSM with interconnected mesopore-networks using an HHP method. J Ceram Soc Jpn 2006, 114: 554-557.

[3] Nakahira A, Takimura M, Yamasaki Y. Synthesis of bulky mesoporous silica (FSM) by hydrothermal hot-pressing method. J Non-Cryst Solids 2007, 353: 4203-4207.

[4] Matamoros-Veloza Z, Yanagisawa K, Rendón-Angeles JC, et al. Preparation of porous glass-ceramics under different hydrothermal hot pressing conditions. Solid State Ionics 2004, 172: 597-600.

[5] Onoki T, Hosoi K, Hashida T. New technique for bonding hydroxyapatite ceramics and titanium by the hydrothermal hot-pressing method. Scripta Mater 2005, 52: 767-770.

[6] Katsuyama S, Kishida A, Ito M. Synthesis of $\mathrm{Na}_{x} \mathrm{Co}_{2} \mathrm{O}_{4}$ by the hydrothermal hot-pressing and its thermoelectric properties. J Alloys Compd 2006, 414: 215-220.

[7] Onoki T, Hosoi K, Hashida T, et al. Effects of titanium surface modifications on bonding behavior of hydroxyapatite ceramics and titanium by hydrothermal hot-pressing. Mat Sci Eng C 2008, 28: 207-212.

[8] Onoda H, Okumoto K, Nakahira A, et al. Mechanochemical effects on the synthesis of copper orthophosphate and cyclo-tetraphosphate bulks by the hydrothermal hot pressing method. Materials 
2009, 2: 1-9.

[9] Onoda H, Sakai R, Nakahira A, et al. Synthesis of porous aluminum phosphate bulks by hydrothermal hot pressing process and their analytical characterizations. Inorg Mater 2009, 45: 1048-1052.

[10] Onoda H, Inagaki Y, Kuwabara A, et al. Synthesis and electrical conductivity of tetra-valent cerium polyphosphate bulks. Phosphorus Res Bull 2009, 23:
20-24.

[11] Min W, Miyahara D, Yokoi K, et al. Thermal and mechanical properties of sintered $\mathrm{LaPO}_{4}-\mathrm{Al}_{2} \mathrm{O}_{3}$ composites. Mater Res Bull 2001, 36: 939-945.

[12] Onoda H, Yoshida A. The synthesis and properties of bulk lanthanum phosphates obtained by hydrothermal hot pressing. J Ceram Process Res 2012, 13: 622-626. 